\title{
A Case Study of Adoption of a Mixed Teaching Mode in the Teaching of English-Chinese Translation Course
}

\author{
Zhiling Wu, Yongqing Guo, Jianjun Wang* \\ Foreign Languages College, Inner Mongolia University, Hohhot, China \\ Email: *imuwzl@163.com
}

How to cite this paper: Wu, Z. L., Guo, Y. Q., \& Wang, J. J. (2021). A Case Study of Adoption of a Mixed Teaching Mode in the Teaching of English-Chinese Translation Course. Chinese Studies, 10, 31-41. https://doi.org/10.4236/chnstd.2021.101003

Received: November 19, 2020

Accepted: January 30, 2021

Published: February 2, 2021

Copyright (๑) 2021 by author(s) and Scientific Research Publishing Inc. This work is licensed under the Creative Commons Attribution International License (CC BY 4.0).

http://creativecommons.org/licenses/by/4.0/

\section{(c) (i) Open Access}

\begin{abstract}
This paper explores the application of Task-Based Learning (TBL), Collaborative-Inquiry Model (CIM) + MOOCs mixed teaching mode in the teaching of "English-Chinese translation" course. When accomplishing learning tasks by groups, students are driven to carry out collaborative learning before class. Students feel compelled to complete specific learning tasks in the form of group cooperation assigned by the teacher through two quality MOOC courses before class. In the case of this translation course, students are required to gain an insight into certain differences between English and Chinese before class from the level of the syntactic structure to that of the semantic meaning. The teacher carefully designs the overall learning task and group learning tasks to ultimately achieve one of the teaching goals of enabling students to introduce Chinese culture in accurate and authentic English, and hence to improve students' abilities in terms of cross-cultural translation and exchange of Chinese culture. The results show that: 1) TBL, CIM + MOOCs mixed teaching mode can cultivate students' abilities to acquire knowledge independently, study with goals and inquiring spirits, and enhance students' awareness of classroom participation; 2) Students can consciously adopt appropriate translation strategies based on their knowledge of the distinct features of English and Chinese, so as to avoid using Chinglish in their translation since they have a real indepth understanding of the differences between the two languages by their autonomous online learning and collaborative discussion in advance; 3) Teaching activities of introducing Chinese culture in English have cultivated and improved students' abilities to convey Chinese culture in accurate English and to tell well Chinese stories in idiomatic English.
\end{abstract}

\section{Keywords}

Mixed Teaching Model, English-Chinese Translation, College Students, Chinese Culture Exchange, English Application Ability 


\section{Introduction}

The ultimate goal of English teaching is communication. The so-called "communication" in English teaching means that English learners can effectively improve their cross-cultural translation and communication abilities while mastering English as a language and understanding Western culture, so as to exchange Chinese culture, tell Chinese stories and let the world understand China.

At present, in the process of college English teaching at Inner Mongolia University, the arrangement of class hours and the teaching content are basically based on the textbooks. Nevertheless, most texts in those college English textbooks are taken from foreign newspapers and magazines, and the majority of which introduce Western society, culture and values. Those texts fully present the true British and American culture, which is of great benefit for students to master a pure foreign language, and understand the Western culture. However, the introduction of Chinese culture is very little and obviously insufficient, which makes students unable to learn useful English expressions of the Chinese culture from their English textbooks. The direct result is that when students express the culture of their mother tongue in English, they are exceedingly short of correct and idiomatic expressions. Students' abilities of telling about the Chinese culture in English are apparently lower than those of telling about the British and American culture. When it comes to Christmas and Valentine's day in foreign countries, students talk about it from the origin to celebration ways with ease and fluency. When it comes to Chinese traditional festivals, such as the Spring Festival and the Dragon Boat Festival, students have something to say but they cannot express them in authentic English. How to cultivate and improve students' abilities to accurately and adequately express Chinese culture in English in cross-cultural communication is becoming an inevitable and urgent task in college English teaching.

Currently, traditional teacher-centered teaching mode is mostly adopted in the teaching of English-Chinese translation course at Inner Mongolia University. The single mode of "teacher-centered teaching, students' after-class homework" results in students' low participation and enthusiasm, and insufficient interaction between teachers and students and between students. This paper explores the application of a mixed teaching model of TBL, CIM and MOOCs to English-Chinese translation teaching for college students at Inner Mongolia University, China. This new teaching mode of "students' pre-class learning, classroom discussion and learning guidance from teachers" reverses the two stages of students' learning process, "receiving" and "digesting", and constructs a real "student-centered, teacher-guiding" personalized collaborative inquiry learning environment, which makes students change from passive learning to active learning and really devote themselves to the learning process. It is intended that specific learning tasks motivate college students to cooperate in English-Chinese translation (Ellis, 2003).

In the traditional evaluation of English-Chinese translation course, students' 
ordinary performance in class accounts for $20 \%$ of the final score, and the final examination of the course accounts for $80 \%$. From the above, we know that in the traditional evaluation of students' learning effects from the course, the final score of the student for this course is mainly determined by the final examination. The traditional learning evaluation pays too much attention to the outcome evaluation and ignores the process evaluation. However, in TBL, CIM + MOOC mixed teaching mode, the process evaluation and outcome evaluation are attached equal importance to, $50 \%$ for the process evaluation and for the outcome evaluation respectively. Questionnaire survey of students' self-assessment of learning effects and curriculum satisfaction was conducted to reflect the implementation effects in TBL, CIM + MOOC mixed teaching mode. It shows that students' consciousness of participation in class has been strengthened and the learning process is paid more attention to by not only the teacher but also the students in particular in the new teaching mode.

The whole curriculum design and teaching process are shown in Figure 1.

\section{Curriculum Design and Teaching Process}

With the help of MOOC platform of Chinese universities, the teacher optimizes the use of online and offline classrooms. Students can use a variety of mobile devices and PC terminals to access and learn the online courses in Chinese universities for knowledge input in advance. Students can watch video to get the anticipated input beforehand in their after-class time, which could develop students' abilities to acquire knowledge independently, study with goals and with inquiring spirits. The traditional teaching mode of "teacher-centered teaching, students' after-class homework" is changed into a new mixed teaching mode in which a new personalized learning environment is constructed, where "students' pre-class learning, classroom discussion and learning guidance from teachers" make students change from passive learning to active learning and really devote themselves to the learning process and increase students' awareness of classroom participation.

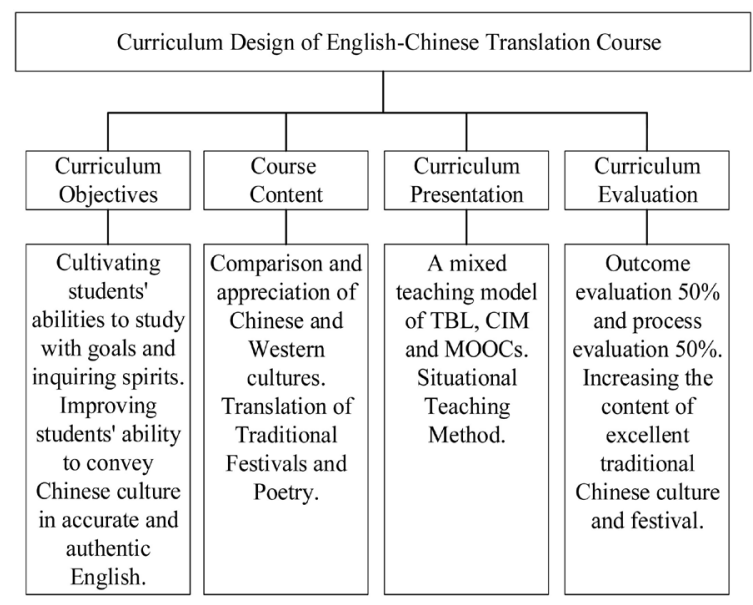

Figure 1. Curriculum design of English-Chinese translation course. 
In the teaching of English-Chinese translation, TBL and CIM are also applied to online and offline MOOC, and students are motivated to cooperate in learning when performing their specific learning tasks. The teacher mainly focuses on the design of learning tasks and learning process, which are divided into several connected modules of teaching. Students work together and discuss with each other to complete online learning in advance. In class, the teacher solves the students' problems and completes the classroom inquiry process. The students change from a state of passive acceptance to that of active learning. They tap up translation ideas through group activities, and are really involved in the learning process. By means of cooperative learning, teacher's explanation and model translation, the teacher can help students understand and learn that the three major differences between English and Chinese have impact on translation, so that they should strain to attain the objective of avoiding excessive Europeanization and Chinglish in their translation. The curriculum design by the teacher plays a key role in this new teaching mode. The teacher is expected to incorporate interesting and effective learning contents to arouse students' enthusiasm. For example, the teacher integrates traditional Chinese cultural festivals into classroom teaching on occasions of traditional festivals to boost students' basic translation skills through Chinese-English translation practice, emphasizing the transformation from input to intake in the English classroom.

The teacher applies a cumulative evaluation, process evaluation and result evaluation to assess students' learning results, which is a multi-angle and multi-mode evaluation, and equal attention is paid to students' learning process as well as the learning outcome in this TBL, CIM + MOOC mixed teaching mode. In this new mixed teaching mode, the contents of brilliant traditional Chinese culture and festivals have been increased in order to improve students' sense of their Chinese culture input and output in English. In the stage of assessment, the translation of words with Chinese cultural characteristics, current affairs and political sentences, as well as the English translation of traditional Chinese festivals such as Spring Festival, Mid-Autumn Festival and Chinese Valentines' day are all covered. In addition, students are required to write practical reports on the press conference of the NPC and CPPCC in order to cultivate their practical translation ability.

The participants of this case study in the application and practice of the TBL, CIM + MOOC mixed teaching mode are 120 students enrolled in 2019 in two classes of Elective Course of English-Chinese Translation at Inner Mongolia University.

Questionnaire survey of students' self-assessment of learning effects and curriculum satisfaction was conducted after the completion of the mixed teaching mode for one semester. The students were asked the following questions.

1) How long did it take you to get prepared for class in the traditional mode?

2) How long did it take you to get prepared for the class in the new mode?

3) How well does the new mode help you to get the intended input before class? 
4) What's good for you to compare and appreciate Chinese and Western cultures?

5) Did (TBL, CIM + MOOCs) mixed teaching mode boost your classroom participation?

6) Could the teaching activities of introducing Chinese culture in English improve your abilities to convey Chinese culture in English?

\section{Application of a Mixed Teaching Model of TBL, CIM and MO0Cs}

To cultivate students' abilities to study with goals and inquiring spirits and improve their abilities to convey Chinese culture in accurate and authentic English, the teacher has added more contents of comparison and appreciation of Chinese and Western cultures to class. In the application of TBL, CIM + MOOC mixed teaching mode to the teaching of English-Chinese translation, the teacher has also integrated the translation of traditional festivals and poetry into the curriculum teaching content and curriculum evaluation framework.

\subsection{A Mixed Teaching Mode Based on M00Cs to Increase Students' Awareness of Classroom Participation}

The teacher takes advantage of MOOC online courses in Chinese universities to design her teaching and push high quality learning resources to the students before class. In the practice of English-Chinese translation, what students translate is not authentic English, and unable to make the original language style and cultural connotation get full transmission. The reason is that students do not have a clear and systematic understanding of the macro and micro differences between English and Chinese. If students do not understand the differences between English and Chinese, they cannot choose appropriate translation strategies according to the characteristics of the two languages.

The teacher chooses A Contrastive Study of English and Chinese and Translation in Practice courses from MOOC platform of Universities of China for the students to conduct autonomous online learning and collaborative discussion in advance.

Students can use a variety of mobile devices and PC terminals to access and learn the online courses in Chinese universities for knowledge input in advance. The students cooperate and inspire each other, they discuss and summarize the main differences between English and Chinese. Because translation skills are summed up on the basis of the differences between English and Chinese, the students are expected to understand the characteristics of English and Chinese systematically and clearly in the mode of group cooperation and discussion. If the students master the origin of translation methods, they can apply translation skills flexibly, which is conducive to their authentic expression in foreign exchange. Thus, correct and idiomatic translations are shared and discussed by the students in group in class. Through classroom practice and discussion, students are familiar with the application of translation skills. 
A mixed teaching mode based on MOOC constructs a real "student-centered, teacher-guiding" personalized collaborative inquiry learning environment. Thus, a new teaching mode of "students' pre-class learning, classroom discussion and learning guidance from teachers" is formed. It aims to make students change from passive learning to active learning and really devote themselves to the learning process and increase students' awareness of classroom participation.

\subsection{TBL, CIM and Situational Teaching Method to Cultivate and Improve Students' Abilities to Convey Chinese Culture in Accurate English}

Students are motivated to cooperate in learning when performing their specific learning tasks after they had an effective input of learning materials through TBL and CIM. The teacher divides the teaching contents into six connected modules, and uses the task-driven flipped classroom and group collaboration learning mode to carry out teaching. First of all, the teacher carefully chooses six topics, which are of great interest to students and can help them to compare and appreciate Chinese and Western cultures. They are 1) a comparison between the Western mainstream culture and Chinese core culture; 2) a comparison of Chinese and Western traditional festivals; 3) Chinese and foreign celebrities; 4) a comparison of Chinese and Western poetry; and 5) Chinese and foreign places of interest; and 6) differences between English and Chinese in syntactic structure and semantic meaning. The whole class is divided into several study groups and the group leader is appointed. Students of the study groups are required to cooperate before class to collect the materials of their selected topic and make PPT, to give their presentations in class. Topic presentations, exchanges and collision of ideas between students make students learn a lot in differences between the Chinese language and the English language, and in abilities of appreciating the Chinese and Western culture. Better comprehension of Chinese and Western cultures is beneficial to students' language learning and communication.

Experiential activities are used in class to guide students to acquire knowledge and skills in their personal learning process. For example, the teacher asks students to make an English sitcom with the theme of "If I were a tour guide, how would I introduce the tourist attractions of Inner Mongolia to foreign tourists." Class activities like this have proved the practical value of English-Chinese translation course, raised students' interest in learning, elevated students' ability to introduce Inner Mongolia culture in English.

In addition, many tourist attractions names in Inner Mongolia contain profound Mongolian culture. The teacher asks students to discuss in group how to use some translation strategies to retain their cultural background as much as possible and to convey fully the cultural connotation of the source language. Through these practical activities, students can truly introduce the unique natural scenery and national culture of Inner Mongolia to foreigners and their translation skills are honed and their abilities of Chinese culture output are improved. 


\subsection{Teaching Activities of Introducing Chinese Culture in English Designed to Develop Students' Abilities to Accurately Tell about the Chinese Culture in English}

On the occasion of the Mid-Autumn Festival, an age-old Chinese festival, the teacher asks students to collect information in groups before class about the topic to be covered in class, like the topic of the origin and customs of the Mid-Autumn Festival, and relates it to the whole class in English. On the National Day, students are encouraged to use English to describe it and all the related celebration activities, which heightens students' national identity and national confidence. These activities have not only developed students' abilities to accurately tell about the Chinese culture in English in cross-cultural communication but also let Western people understand our traditional Chinese values like "valuing family reunion, esteem for parents".

It needs to be pointed out that the choice of translation materials should be not too easy, but be challenging enough to stimulate students' desire of accomplishing them. The teacher goes out of her way to collect teaching contents as translation materials, like China's social and economic developments, history and culture, scientific and technological achievements and hot social issues for the students, for instance, China has developed rapidly in science and technology, realizing a leap from "manufactured in China" to "created in China" in some areas. Students are guided by the teacher to talk about things like the first domestically built aircraft carrier, the Tianzhou-1 docked with the Tian gong 2, and the C919 flight. The teacher introduces such topics for students to translate into English to strengthen students' confidence in English abilities and national pride. It has not only changed the situation that the English class more often prioritizes input rather than output, but also has inspired students' patriotic feelings, national pride and patriotic consciousness. Students' sense of achievements in their abilities will be heightened when they succeed in producing good translations through their hard work, which realizes the goal of improvement in knowledge, ability and quality.

In classroom teaching, the teacher inspires students to explore the essence of the Chinese culture and taste the beauty of the Chinese language in the translation of poetry. Such a sentence as "A letter from home always means a lot" is provided for students to translate. The students are encouraged to discuss in a small group how to translate it correctly, expressing a person's longing and excitement when receiving a letter from home. Some students came up with an idea that it could be translated into “家书抵万金”, which is a line from the poem Spring Prospect, written by Dufu, the greatest realist poet of the Tang Dynasty. The line means that it is more precious to receive a letter from home than to receive lots and lots of gold, which fully depicts the homesick feeling of a person far away from home. In this way, students understand the classical poetry written by excellent poets, and in a sense, these great classical poems will refresh in students' heart and never fade in their charms. Through this English version, native English speakers will also be able to appreciate our classical poetry and get 
to understand Chinese culture better.

In order to enable students to understand more literary classics, the teacher has selected a popular short poem on the Internet to guide students to translate.

"You say that you love rain, but you open your umbrella when it rains. You say that you love me too...

You say that you love rain, but you open your umbrella when it rains.

You say that you love the sun, but you find a shadow spot when the sun shines.

You say that you love the wind, but you close your windows when wind blows.

This is why I am afraid, because you say that you love me too."

There are eight translation versions of this short poem on the Internet, including literal version, literary version, Book of Songs version, Lisao version and the five-character quatrain version etc. When appreciating these versions, students will be aware of the extensiveness and profundity of the Chinese language, the beauty and richness of the Chinese language, and thus improve students' ability of poetry translation.

\section{Teaching Evaluation}

This course has been approved as an online and offline first-rate course of Inner Mongolia University in 2020.In the new teaching evaluation, the course is evaluated from different perspectives and in different ways including the way of combining process evaluation with outcome evaluation. In the teaching plan, the process evaluation and outcome evaluation are attached equal importance to, $50 \%$ for the process evaluation and for the outcome evaluation respectively. Process assessment accounts for $50 \%$ of the total score, including $20 \%$ of classroom performance and $30 \%$ of online learning. Online learning consists of four parts which are summary exercises $45 \%$, unit test $25 \%$, course discussion $10 \%$ and final exam $20 \%$.

In the process evaluation, students' performances in such respects as traditional culture, advanced culture and national culture are included and assessed in the form of examinations. For instance, translation items like words with Chinese cultural characteristics, passages about current hot spots and Chinese traditional festivals, such as Spring Festival, Mid-Autumn Festival, Qixi Festival, etc. are chosen for students to translate into English with their accurate cultural connotations.

Outcome assessment accounts for $50 \%$ of the total score, in which the NPC and CPPCC report in 2020 was chosen for the students to finish translation practice reports, which aims to let the students put what they have learned into practice.

\section{Teaching Effects}

As the main driving force of the mixed teaching is students, the implementation effect is generally reflected by the feedback of college students after class and their self-assessment of learning effects and curriculum satisfaction (Spanjers et 
al., 2015; Rahman et al, 2015; Ekwunife-Orakwue \& Teng, 2014; Owston et al, 2013).

After the completion of the reform of the mixed teaching mode, questionnaire surveys and interviews were conducted to evaluate the effect of the integration path. A total of 120 questionnaires were distributed and all valid questionnaires were collected.

The questionnaire shows that $98 \%$ of the students have significantly improved their understanding of Chinese excellent traditional culture, and their sense of national pride has been greatly improved, and they are more confident in the excellent Chinese traditional culture; $88 \%$ of the students are confident that they are capable of conducting in-depth English discussion and translation on a certain key point of Chinese excellent traditional culture.

The results of the questionnaire survey also show that: $96.5 \%$ of the students said that the online and offline mixed teaching mode enhanced the awareness of classroom participation; $94.6 \%$ of the students said that the classroom atmosphere was active; $95.6 \%$ of the students said that task-based teaching method, collaborative research mode, situational teaching method increased the practicability of English-Chinese translation teaching, increased students' interest in learning, and improved their ability to introduce Inner Mongolia culture in English, and also improved their overall English application ability.

The survey on the pre-class learning time is as follows: under the traditional mode, $70 \%$ of the students do not preview before class, and $30 \%$ of the students who prepare for the class usually spend less than 30 minutes. Under the new mode, $99 \%$ of the students have studied before class, and two thirds of the students have studied for one to two hours or more before class. They think that the learning before class is very important for the practice and discussion in the classroom. If the learning materials are not carefully studied and mastered before class, it will directly affect the classroom learning and discussion.

24 college students were selected randomly from different colleges for open interviews. In the interviews, the students fully affirmed the improvement of students' English-Chinese translation abilities, especially in interpreting the longstanding Chinese culture in accurate and understandable English during the study of this course.

One student states: "After careful study and analysis of this NPC and CPPCC report, I have put what I have learned into practice, and I have more experience of the breadth and profundity of Chinese culture, the power of Chinese spokesmen and the excellent professional knowledge and skills of Chinese translators. At the same time, I also realize the importance of cultural soft power and will actively promote Chinese traditional culture."

One student comments on the merit of the course: "We understand and conclude the major differences between English and Chinese by means of cooperative learning and the teacher's explanation and case translation. After I have a deep understanding of the differences between English and Chinese, I can consciously and appropriately choose translation strategies according to the charac- 
teristics of the two languages so as to ensure that my translated and expression of Chinese culture is smooth, fluent and in line with the target language readers' expression habits."

Another student put it in this way: "The special exhibition and exchange of Chinese and Western cultures in the classroom provides us with more opportunities for cultural exchange and practice, and enables us to actively participate in the discussion, so as to effectively improve our English level and cultivate our ability to compare and appreciate Chinese and Western cultures."

One student said: "the teacher guides us to do a good job in the input of learning materials before class, which improves our interest and ability of autonomous learning; the enhanced interaction with teachers and students in class also cultivates our ability to acquire knowledge independently and study with goals."

\section{Conclusion}

The one-year practical teaching of English Chinese translation shows that the mixed teaching mode of TBL, CIM + MOOC can construct a real personalized collaborative inquiry learning environment, where "students' pre-class learning, classroom discussion and learning guidance from teachers" make students change from passive learning to active learning and really devote themselves to the learning process and increase students' awareness of classroom participation. Students are more actively involved in classroom teaching activities. The teaching mode of task-driven group cooperative enables students to understand in advance the differences between English and Chinese and the translation methods adopted accordingly, so as to apply the translation methods learned in advance in classroom translation practice more consciously. Through cooperative learning and mutual inspiration, the students have discussed and summarized the main differences between English and Chinese in three aspects. According to the characteristics of English and Chinese, appropriate translation strategies are selected to avoid Chinglish phenomenon in their translation.

In the classroom teaching of English-Chinese translation the teacher grasps the national festivals and the current hot issues to practice the expression of traditional culture and contemporary advanced culture. These translation activities not only improve the situation of emphasizing input over output in English classroom, but also cultivate students' ability to accurately express Chinese culture in English in cross-cultural communication and improve students' level of expressing Chinese culture in English.

In one year's teaching exploration and practice, the mixed mode of TBL, CIM + MOOC has enabled 120 students of various disciplines and majors in Inner Mongolia University to improve their interest in learning, improve their learning efficiency, and proper choice of translation strategies, so as to avoid Chinglish phenomenon existing in their translation. The mixed mode of TBL, CIM + MOOC has improved students' abilities to express Chinese culture in accurate and 
idiomatic English. It is expected that it can provide reference for the teaching of English-Chinese translation and other similar courses in other brother universities and colleges of Inner Mongolia Autonomous Region.

\section{Acknowledgements}

This work was financially supported by Research and Construction Project of Undergraduate Teaching Reform of Inner Mongolia University (No. NDJG-20-27).

\section{Conflicts of Interest}

The authors declare no conflicts of interest regarding the publication of this paper.

\section{References}

Ekwunife-Orakwue, K. C. V., \& Teng, T. L. (2014). The Impact of Transactional Distance Dialogic Interactions on Student Learning Outcomes in Online and Blended Environments. Computers \& Education, 78, 414-427.

https://doi.org/10.1016/j.compedu.2014.06.011

Ellis, R. (2003). Task-Based Language Learning and Teaching. Oxford: Oxford University Press.

Owston, R., York, D., \& Murtha, S. (2013). Student Perceptions and Achievement in a University Blended Learning Strategic Initiative. The Internet and Higher Education, 18, 38-46. https://doi.org/10.1016/j.iheduc.2012.12.003

Rahman, N. A. A., Hussein, N., \& Aluwi, A. H. (2015). Satisfaction on Blended Learning in a Public Higher Education Institution: What Factors Matter? Procedia-Social and Behavioral Sciences, 211, 768-775. https://doi.org/10.1016/j.sbspro.2015.11.107

Spanjers, I. A. E., Könings, K. D., Leppink, J., Verstegen, D. M. L., Jong, N., Czabanowska, K., \& Merriënboer, J. J. G. (2015). The Promised Land of Blended Learning: Quizzes as a Moderator. Educational Research Review, 15, 59-74.

https://doi.org/10.1016/j.edurev.2015.05.001 